\section{Improvement of diabetic patients nursing care by the development of educational programs}

\author{
Bakalis Vissarion, ${ }^{1}$ Maria Malliarou, ${ }^{2}$ \\ Paraskevi Theofilou, ${ }^{3}$ Sofia Zyga 4 \\ 1 Iaso General Hospital or Thessaly, Larisa, \\ Thessaly; 2Nursing Department, 404 \\ General Military Hospital, Technological \\ Institution of Larisa, Thessaly; \\ 3Department of Kinesiology, Centre for \\ Research and Technology, Health and \\ Quality of Life Research Group, Trikala, \\ Thessaly; ${ }^{4}$ Department of Nursing, \\ Faculty of Human Movement and Quality \\ of Life Sciences, University of \\ Peloponnese, Sparta, Lakonia, Greece
}

\begin{abstract}
Diabetes is a major health problem with many social and economic consequences in general population. The importance of education in the diabetic patient and his family, led to the development of diabetes clinical nurse specialist. The role of diabetes clinical nurse specialist is essential and crucial to the hospitals and the community, in order to form a relationship with the diabetic patient and his/her family. In this way health is promoted to the maximum extent possible. In conclusion educational programs help patients with diabetes to obtain information about their condition and improve their self-care skills.
\end{abstract}

\section{Introduction}

Diabetes is among the chronic diseases that feature significantly in public health and are the greatest cause of disability and premature death in Europe. Diabetes is a chronic, and largely preventable, disease that can lead to cardiovascular disease, blindness, kidney failure, loss of limbs and loss of life. It causes suffering and hardship for the approximately 60 million people in the European Region currently living with the disease, while also straining its health systems. ${ }^{1}$

Prevalence of diabetes is increasing in the European Region, already reaching rates of 10 $12 \%$ of the population in some countries. This increase is strongly associated with risk factors such as overweight and obesity, unhealthy diets, physical inactivity and socioeconomic disadvantage. These risk factors also contribute to the development of the other three non-communicable diseases (NCDs) cardiovascular disease, chronic respiratory diseases and cancer, making imperative the prevention of diabetes. ${ }^{1}$

According to the World Health Organization, who 346 million people worldwide have diabetes. In 2004, an estimated 3.4 million people died from consequences of high blood sugar. More than $80 \%$ of diabetes deaths occur in lowand middle-income countries. WHO projects that diabetes death will double between 2005 and 2030. Healthy diet, regular physical activity, maintaining a normal body weight and avoiding tobacco use can prevent or delay the onset of type 2 diabetes. ${ }^{2}$

The incidence of diabetes in Greece is estimated at $8 \% .3,4$ Diabetes is a progressive disease that affects the patient's physical, cognitive, emotional, familial and social functions and well-being. ${ }^{5}$ Many researchers have, in recent years, shown particular interest in diabetes and have systematically focused their attention on the training of the diabetic patient.6,7

One of the most significant developments is that of specialist clinical nurses to educate diabetics (adults and children) and their families. ${ }^{8}$

\section{Diabetes nurse specialist}

Nursing is a multi-aspect profession that calls for a high degree of specialist knowledge. That is why Johnson (1966) recommends the introduction of the Specialist Clinical Nurse. ${ }^{9}$ In the late $1960 \mathrm{~s}$ it became necessary to have suitable postgraduate training, 10 in order to be qualified as a Specialist Clinical Nurse in North America.

Specialty in nursing presupposes a higher degree of specialist knowledge, skills and necessary qualities in the specific area than basic training in General nursing provides.

Shari defines the specialist clinical nurse as a nurse with additional training, who provides direct nursing for specific patients in a particular area of nursing. 11 The specialist clinical diabetes nurse is defined as a health care professional who possesses basic knowledge and skills in life and social sciences, communication and counseling, and is experienced in the care of diabetics. ${ }^{12,13}$ The number of Specialist Diabetes Clinical Nurses in Great Britain has increased steadily in recent years because of the increased incidence of diabetes in children coupled with increased awareness of the needs these children have. 14

The Diabetes Clinical Nurse Specialist is responsible for training diabetic children and their careers. Nurses work in hospitals and in the community in close collaboration with other health professionals, with the children
Correspondence: Sofia Zyga, Department of Nursing, Faculty of Human Movement and Quality of Life Sciences, University of Peloponnese, Leonidou 3, Sparta Lakonias, Greece.

Tel. +30.273.108.9725

E-mail: zygas@uop.gr

Key words: diabetes, diabetes clinical nurse specialist, training.

Contributions: the authors contributed equally.

Conflict of interests: the authors declare no potential conflict of interests.

Received for publication: 12 January 2013.

Revision received: 18 February 2013.

Accepted for publication: 18 February 2013.

This work is licensed under a Creative Commons Attribution NonCommercial 3.0 License (CC BYNC 3.0).

(C) Copyright B. Vissarion et al., 2014

Licensee PAGEPress, Italy

Health Psychology Research 2014; 2:931

doi:10.4081/hpr.2014.931

themselves, their families and teachers. ${ }^{15,16}$

Harmic and Fenton divide the work of the Clinical Nurse Specialist into direct and indirect activities. ${ }^{15,16}$

Direct work includes the following: i) providing regular nursing for a small group of patients; ii) analyzing complex clinical problems; iii) selecting and applying methods; iv) participating in clinical meetings; v) training patients individually or in groups; vi) creating support groups for patients and their families; vi) acting in crises; vii) providing emotional and social support for patients and families.

Indirect work includes the following: i) creating staff support groups; ii) collaborating with nursing staff to produce care plans; iii) developing methods and procedures; iv) participating in activities designed to maintain quality; v) referring patients to other services.

\section{The diabetes nurse specialist and training}

The clinical nurse specialist plays a definitive role in the hospital, in the community and at school. Clinical Specialist nursing is a new approach and aims to improve the quality of the training a diabetic receives. The Clinical Diabetes Nurse Specialist has specific responsibilities regarding the assessment of the diabetic patient. Assessment is not only about how knowledgeable patients are of their condition, but also of what they need in the way of 
training and how prepared they are to learn.17,18 Specific instruction concerning medication, equipment, diet/nutrition must be incorporated in all patient educational programs. All those programs must result in documentation that the patient and family understand what has been taught. ${ }^{19}$

The burden of managing diabetes is on the parents to a greater or lesser degree, depending on the age of the child. Continuous training of parents and child is therefore an important factor in the effective treatment of the disease. ${ }^{20}$ Training should not be confined to the patient only, but should extend to include at least one more member of the family. ${ }^{21}$

Even so, the consensus emerging from practical studies seems to point more and more to the fact that children and adolescents who undertake more responsibility in the management of their diabetes treatment make more mistakes in maintaining the daily treatment regime, are less inclined to adhere to the program and have less control over their metabolism than those whose parents are more involved in their treatment routine. 5,22

\section{Review outcomes}

A literature review was done using key words such as diabetic training, nurse, educational programs in Google scholar and research outcomes that describe the significance of training of diabetics are described in this article. Hernandez and Williamson did research at a diabetic training center in Canada with a view to assessing the impact of training and awareness on young people with diabetes type I. ${ }^{23}$ The twenty-nine diabetic children who took part in the study all attended a one-hour training session on diabetes. Data was gathered from questionnaires that the subjects filled in immediately before and after the training session and a further questionnaire that they filled in one year later. The findings indicated that the session produced favorable short term and long term results in promoting awareness of diabetes, as well as the beneficial results of keeping blood sugar levels within normal limits, pointing out the value of educating patients.

Another study carried out by Polonsky et $a l .{ }^{24}$ at the Tripler Army Medical Centre in Hawaii assessed the results of a specific training program for diabetic patients (Diabetes Outpatient Intensive Treatment). The first stage involved 167 people and the second stage (6 months after training) involved 117. The data, gathered through a variety of psychometric tools, demonstrated that participants were more aware of blood sugar levels and sought greater medical supervision. Moreover, their eating habits improved and they reduced their intake of carbohydrate and lipids.

Though there are studies that are in favor of the positive results of diabetes training for adults and children, there are others that draw different conclusions. The research conducted by Hampson et al. 25 is a case in point. This systematic review looked into the beneficial effects on a number of outcomes of the interventions in children with diabetes type I, and aimed specifically at improving diabetes management. It gives a detailed description of 62 studies, most of which were carried out in the US and Canada. The studies were mainly quantitative studies using the Randomized Controlled Trials (RCT) approach. The trials were carried out in a variety of institutions (hospitals, clinics and training centers) with an average of 53.8 people participating. The results showed that training and socio-psychological intervention was of limited benefit to the diabetic patient. Even so, the conclusion was that the various forms of intervention may produce better results when specific aspects of diabetes are targeted rather than adopting a general approach to the whole problem.

A study by Cowan et al. ${ }^{26}$ at the University Hospital of Wales Pediatric Clinic assessed the impact of Specialist Diabetes Clinical Nurses in diabetes care management over a threeyear period. The study compared the care management of 154 diabetic children before and after being put on the Specialist Clinical Diabetes Nursing program. Study of the data on clinical management and blood sugar level management showed significant improvement in training the diabetic children, in their clinical management and in admissions to the hospital during their Specialist Diabetes Clinical Nursing. Lowes took this study a step further and assessed the effect of Specialist Diabetes Clinical Nursing on diabetic children two years after starting the programme. ${ }^{13}$ The results showed a significant (50\%) drop in the time children who had been diagnosed as diabetic spent in hospital. The seven training sessions for children and their parents were very well attended (91\%) and children and parents alike had very positive feelings about the content of the sessions. Though the results of this study favor the introduction of Specialist Diabetes Clinical Nursing in the care and management of childhood diabetes, the small number of subjects and geographical limitations of the study mean that the results cannot be presumed generally applicable.

Moyer set out to compare the care provided for diabetic children and their parents at diabetes clinics with and without Specialist Diabetes Clinical Nursing programmes. ${ }^{27}$ There were 161 families in the study, 89 of whom attended clinics without Specialist Diabetes Clinical Nursing programs. Both quantitative and qualitative data were gathered. The results showed that children who had access to Specialist Diabetes Clinical Nursing programs demonstrated higher levels of awareness of issues related to diabetes and the techniques of administering insulin than children who had no such access.

Another study by Tselika-Garfe et al. ${ }^{28}$ carried out at P. and A. Kyriakou Paediatric Hospital in Athens set out to look into problems that adolescent patients with diabetes face at home, at school and in the community. Their subject group consisted of 56 adolescents between the ages of 11 to $19,87.5 \%$ of whom injected themselves with their insulin. Even so, only one of their numbers was aware of the implications of insulin treatment. The only source of information for most of these adolescents was the doctor at the hospital or another doctor. The results of the study show how important the provision of information is to adolescents with diabetes. Nurses with special knowledge in diabetes have an important role to play in training patients and dealing with complications arising from the disease.

\section{Conclusions}

Diabetes is a condition that a significant number of people have to live with. Coping with the disease requires knowledge of its nature and ways of adapting to the new way of life it imposes. Nowadays, diabetes is usually managed by a team of professionals consisting of doctors, nurses, psychologists and dieticians who specialize in the disease and help sufferers and their families adapt to the new way of life while also keeping the disease under control. Training is the key to improving the quality of life for diabetes sufferers.

Well-trained, experienced Specialist Diabetes Clinical Nurses provide better patient and career training, are more committed, are better listeners and empathize more with their patients. ${ }^{29}$ They inspire trust and make their diabetic patients feel secure so they are more willing to co-operate. ${ }^{29}$ They also help patients turn their mistakes into learning experiences which provide them with correct solutions in managing their disease. Specialist Diabetes Clinical Nurses encourage self-care and medication management. They play a more active part in prescribing medication and willingly take on more responsibility than general medical practitioners. ${ }^{29}$ It is the parents that provide support and care for diabetic children in the initial stages of the disease and they often need more psychological support in order to meet the challenges of the demanding care program they have to adhere to for their children. The care program focuses mainly on the times of day when blood sugar levels have to be measured and insulin injections have to be given. It is the Specialist Diabetes Clinical 
Nurse who helps parents in the role of caring for their child by providing the right information and teaching the skills and techniques they need to manage this chronic disease. ${ }^{30}$ Specialist Diabetes Clinical Nurses also need to collaborate with parents to ensure continued care of the children when they are discharged from hospital. Consequently, Nurses certified in this area are needed to educate patients and prospective patients about diabetes, and discuss diabetes prevention and care.

\section{References}

1. Shehadeh A, Regan TJ. Cardiac consequences of diabetes mellitus. Clin Cardiol 1995;18:301-5.

2. WHO. Country and regional data on diabetes. 2012 Avaliable from: http://www. who.int/diabetes/facts/world_figures/en/. Accessed on: December 2012.

3. Curtis JA, Hagerty D. Managing diabetes in childhood and adolescence. Can Fam Physician 2002;48:499-509.

4. Gerogianni SK, Gerogianni GK. The diabetic leg. The role of nursing in prevention and effective treatment. Nosileftiki 2007;46:493-500. [Article in Greek].

5 . Voliotis K. The role of training in the treatment of sugar diabetes. Ellenika Diabetologika Chronika 1988;23:105-9.

6. Lemonidou CV. The role of the specialist clinical nurse. Nosileftiki 1997;3:189-97. [Article in Greek].

7. Alberti KGMM, Zimmet PZ. Definition, diagnosis and classification of diabetes mellitus and its complications. Part 1: diagnosis and classification of diabetes mellitus. Provisional report of a WHO Consultation. Diabet Med 1998;15:539-53.

8. Dimitriadou E. The diabetes nurse and training in self care. Nosileftiki 1995;3:209-14. [Article in Greek].

9. Jonsson L, Hallstrom I, Lundqvist A. A multi-disciplinary education process relat- ed to the discharging of children from hospital when the child has been diagnosed with type 1 diabetes: a qualitative study. BMC Paediatrics 2010;10:1-10.

10. Royal College of Nursing, Paediatric diabetes special Interest Group. The role and qualifications of the nurse specializing in paediatric diabetes: a working party report. London: Royal College of Nursing; 2006.

11. Shari B. Clinical nurse specialists are not new. Physicians News Digest. Available from: www. http://physiciansnews.com/discussion/baron.html. Accessed on: June 2012.

12. Lahana S, Gerogianni G. The specialist clinical nurse: a definition and explanation of the term. Nosileftiki 2002;1:43-54. [Article in Greek].

13. Lowes L. Evaluation of a paediatric specialist nurse post. Br J Nurs 1997;6:625-33.

14. Cane J, Richardson H. The role of the paediatric diabetes specialist nurse. In: Court S, Namb B, eds. Childhood and adolescents diabetes. Chichester: John Wiley \& Sons; 1997.

15. Harmic AB. A model for development evaluation strategies. In: Harmic AB, Spoross $\mathrm{J}$, eds. The clinical nurse specialist in theory and practice. New York: Grunne \& Stratton; 1983.

16. Fenton MV. Identifying competencies of clinical nurse specialists. J Nurs Admin 1985;15:100-16.

17. Moyer A. Caring for a child with diabetes: the effect of specialist nurse care on parents' needs and concerns. J Adv Nurs 1989;14:536-45.

18. Sigurdardóttir ÁK. Nurse specialists' perceptions of their role and function in relation to starting an adult diabetic on insulin. J Clin Nurs 1999;8:512-8.

19. Trocino L, Byers JF, Peach AG. Nurses' attitudes toward patient and family education: implications for clinical nurse specialists. Clin Nurse Spec 1997;11:77-84.

20. Guthrie DW, Guthrie RA. Nursing management of diabetes mellitus: a guide to the pattern approach. 4th ed. New York: Springer Publication; 1997.

21. Tsamasiros G. The impact of insulin dependent diabetes on family life (on line). The Diabetes Society of Greece, 1998.

22. Ingersoll GM, Orr DP, Herrold AJ, Golden MP. Cognitive maturity and self management among adolescents with insulindependent diabetes mellitus. J Pediat 1986;108:620-3.

23. Hernandez AC, Williamson KM. Evaluation of a self-awareness education session for youth with type 1 diabetes. Pediatr Nurs 2004;30:459-64.

24. Polonsky WH, Earles J, Smith S, et al. Integrating medical management with diabetes self-management training. Psychology 2003;10:585-95.

25. Hampson SE, Skinner TC, Hart J, et al. Effects of educational and psychosocial interventions of adolescents with diabetes mellitus: a systematic review. Health Technol Assess 2001;5:1015-23.

26. Cowan FJ, Warner JT, Lowes LM, et al. Auditing paediatric diabetes care and the impact of a specialist nurse trained in paediatric diabetes. Arch Dis Child 1997;77: 109-14.

27. Moyer A. The specialist nurse and the child with diabetes. Senior Nurse 1987;7:31-9.

28. Tselika-Garfe A, Parava M, Stoikidou M, et al. The problems of adolescents with youth diabetes: the role of the health visitor. Nosileftiki 2004;43:226-36. [Article in Greek].

29. Siminerio LM, Funnell MM, Peyrot M, Rubin RR. US nurses' perceptions of their role in diabetes care. Diabetes Educator 2007;33:152-62.

30. Vlahioti E, Matziou V, Tsoumakas K, et al. Exploring factors that impact on the selfesteem of children with youth diabetes. Nosileftiki 2008;47:507-16. [Article in Greek]. 